\title{
Lymphocytic meningoradiculitis and encephalomyelitis due to Borrelia burgdorferi: a clinical and serological study of 18 cases
}

\author{
C J M SINDIC,* A DEPRE,* G BIGAIGNON, $†$ P F GOUBAU, $\ddagger$ P HELLA, $\S$ \\ C LATERRE*
}

From Service de Neurologie, Cliniques Universitaires Saint-Luc, ${ }^{*}$ Brussels, Laboratoire de Sérologie, Cliniques Universitaires Saint-Luc, $\dagger$ Brussels, Dienst microbiologie, UZ St Raphaël, Leuven, $\ddagger$ and Cliniques

Saint-Camille, Namur,§ Belgium

SUMMARY Clinical features of 18 patients with either lymphocytic meningoradiculitis $(\mathrm{n}=17)$ or chronic encephalomyelitis $(\mathrm{n}=1)$ due to Borrelia burgdorferi are reported. Arthropod bites were recorded in only seven patients. High titres of anti $B$ burgdorferi antibodies were detected in sera from all patients and in CSF from 12 out of 17 patients tested. All patients had CSF abnormalities especially pleocytosis and oligoclonal bands. A falsely positive syphilitic serology was observed in the CSF from the patient with encephalomyelitis.

Lymphocytic meningoradiculitis is a radicular neuralgia associated with chronic lymphocytic pleocytosis in cerebrospinal fluid (CSF) generally without meningismus. The disease is characterised by neurological defects (unilateral or bilateral peripheral facial palsies as well as disseminated radiculopathies) and often by intensive pain, sometimes radiating and migrating. In some cases a viral agent is detected, such as genital herpes virus type 2 or herpes zoster. ${ }^{12}$ Most cases, however, had no known infectious causal agent, especially those following a tick bite close to which an erythema chronicum migrans may appear. ${ }^{3}$ Such cases were reported predominantly during summer among adults living in central Europe with a cluster around Würzburg (West Germany) and known under the name of "Bannwarth's syndrome". 4

Lymphocytic meningoradiculitis occurs also in the United States in some patients with Lyme disease. ${ }^{5}$ This disease was first described as a recurrent or migrating mono- or oligoarthritis associated with erythema chronicum migrans which appeared in late summer among children and some adults in Lyme, Connecticut. $^{6}$ It soon became apparent that the disease was also endemic in other regions and was a multisystemic disease with cardiac and neurological

Address for reprint requests: Dr C J M Sindic, Service de Neurologie, Cliniques Universitaires Saint Luc, Brussels, Belgium.

Received 20 February 1987. Accepted 1 May 1987 involvement. ${ }^{7}$ Epidemiological studies suggested that ticks were the vector of transmission. ${ }^{8}$ More recently a spirochete was isolated from these ticks ${ }^{9}$; the same spirochete was also recovered from the blood, skin and CSF of patients with Lyme disease. ${ }^{10}{ }^{11}$ In addition European patients with Bannwarth's syndrome had IgM and IgG antibodies to this Lyme-disease associated spirochete ${ }^{12}$ and spirochetes were also isolated from the CSF of some European patients with lymphocytic meningoradiculitis. ${ }^{13}$ Genetic and phenotypic studies showed that this spirochete represents a new species of borrelia which has been named Borrelia burgdorferi. ${ }^{14}$ European strains are antigenically heterogeneous but at least some are closely related to American strains responsible for Lyme disease. ${ }^{15}$ In addition to lymphocytic meningoradiculitis $B$ burgdorferi infections may involve the brain tissue and the spinal cord; chronic encephalitis and myelitis are known to occur in Lyme disease as well as in European patients infected by $B$ burgdorferi. ${ }^{16-20}$

These new data prompted us to re-analyse the clinical picture and the biological samples from 17 patients with lymphocytic meningoradiculitis and from one patient with a chronic encephalomyelitis observed during the period 1976-1986. Cases with clinical and serologically proven viral infections were excluded.

\section{Material and methods}

CSF from 17 patients with lymphocytic meningoradiculitis 
and one patient with chronic encephalomyelitis were obtained by spinal puncture for routine analysis. After centrifugation, aliquots of $0.5-2 \mathrm{ml}$ were kept frozen at $-20^{\circ} \mathrm{C}$. In most cases, blood was collected on the same day. The total protein content of CSF was determined by nephelometry. Albumin and IgG in both CSF and serum and also IgA and IgM in serum were assayed by immunonephelometry (Auto Analyser II, Technicon, Tarrytown). IgA and IgM in CSF were assayed by immunoassay by particle counting (IMPACT). ${ }^{21}$ The local production of immunoglobulins was estimated by calculation of indices for IgG, IgM and IgA. Our reference limits are 0.69, 0.079 and 0.45, respectively, above which local production can be assumed. ${ }^{22}$ The CSF protein profiles were studied by agar gel electrophoresis and classified as "normal", "transudatetype" or "oligoclonal". 23

The antigen used in ELISA tests was the N34 strain of $B$ burgdorferi isolated in 1983 from a tick Ixodes ricinus in the Eifel (West-Germany) (kindly provided by Prof Dr R Ackermann). Spirochetes from a 5 day old culture in a modified BSK II medium ${ }^{24}$ were washed and centrifuged once at $3500 \mathrm{rpm}$ for 20 minutes and then three times for 10 minutes. The final solution of washed $B$ burgdorferi $(200 \mu \mathrm{g} / \mathrm{ml})$ was sonicated eight times for 15 seconds with intervals of 45 seconds at intensity 4 (Branson Sonifier, Danbury Corporation, USA). This $1 \mathrm{ml}$ solution was added to $10 \mathrm{ml}$ of a coating solution of $\mathrm{pH} 10 \cdot 3$ from which $100 \mu \mathrm{l}$ aliquots were pipetted into the test wells of a microtitre plate (Linbro, Flow Laboratories, McLean, Virginia, USA). Sera and CSF samples were tested according to our ELISA method for other zoonotic diseases using newborn calf serum (NCS); wells incubated at ambient temperature with $50 \mu \mathrm{l}$ of NCS for 15 minutes received either $200 \mu \mathrm{l}$ of serum sample diluted $1 / 100$ in PBS-Tween $20(0.5 \%)$ or $50 \mu 1$ of CSF sample diluted $1 / 5$ in the same PBS-Tween 20 . After 30 minutes at $37^{\circ} \mathrm{C}$, the plate was washed four times with PBS. Anti-human total Ig or IgM horseradish peroxidase labelled rabbit antiserum (Dako, Denmark), diluted $1 / 625$ with $20 \%$ NCS in PBS-Tween 20, was added to each well and incubated for 30 minutes at $37^{\circ} \mathrm{C}$. The microplate was then washed four times with PBS and incubated for 30 minutes at $37^{\circ} \mathrm{C}$ with the substrate, $2,2^{\prime}$ azinobis 3 ethyl benz thiazoline sulfonic acid (ABTS) (Sigma, St Louis, USA). All the tests and blank values were read on a Titertek Multiskan spectrophotometer (Flow Laboratories) at 405 and $414 \mathrm{~nm}$. In each assay a positive and a negative control were included. The experimentally determined cut-off values for optical density (OD) were: 180 for total Ig in serum samples; 80 for IgM in serum and 80 for total Ig in CSF samples. Serum samples were also tested with a classic immunofluorescence test using whole $B$ burgdorferi as antigen; all were positive with titres between $1 / 128$ and $1 / 2.048$ (cut off: $1 / 64$ ). In addition, all serum and CSF samples were tested for syphilis serology using the Venereal Disease Research Laboratory (VDRL) test, the Treponema Pallidum Hemagglutination (TPHA) and the Immunofluoresence (IF) test.

\section{Results}

\section{CLINICAL DATA}

(a) Patients with lymphocytic meningoradiculitis (table 1) Patient 1 A 65 year old woman was bitten by a tick in the region of the right T12 dermatome on 19 July 1976 . Three weeks later, she complained of painful dysaesthesia in the same area. Neurological examination revealed a right painful hypoaesthesia from T6 to T12 with a weakness of the right abdominal muscles. The patient recovered completely within 6 months.

Patient 2 A 55 year old man suffered from headache on 12 July 1979 and pain in the right C8-T1 dermatome. A few days later, painful paraesthesiae were noted in the two arms, shoulders and neck. A right facial palsy appeared 2 days later and corticosteroids were started. He was hospitalised 2 months after the clinical onset and the neurological examination showed a bilateral hypoaesthesia in the dermatomes from $\mathrm{C} 8$ to T8, amyotrophy of the left shoulder and absence of the triceps muscles reflexes. The facial palsy had completely recovered. Recovery was slow but complete.

Patient 3 In August 1979, a 44 year old man presented symptoms of lumbar pain radiating in the thighs followed by a radicular pain in both arms. Two months later, he complained of a painful bilateral hypoaesthesia in the dermatomes T5-L1. Neurological examination was otherwise normal. Muscle stretch reflexes were weak but present, and no facial palsy was noted. Tick bite and erythema migrans were not reported by the patient. In November 1979, painful paraesthesiae were still present in the left hypochondrium, the left foot and both hands. In May 1980, the patient relapsed and the clinical examination revealed a right hemihypoaesthesia below the T5 dermatome including the right leg. All these symptoms disappeared spontaneously and the neurological examination was normal in June 80 and February 81 .

Patient 4 A 43 year old man suffered from rachialgia on 24

Table 1 Main clinical features of 17 patients with lymphocytic meningoradiculitis

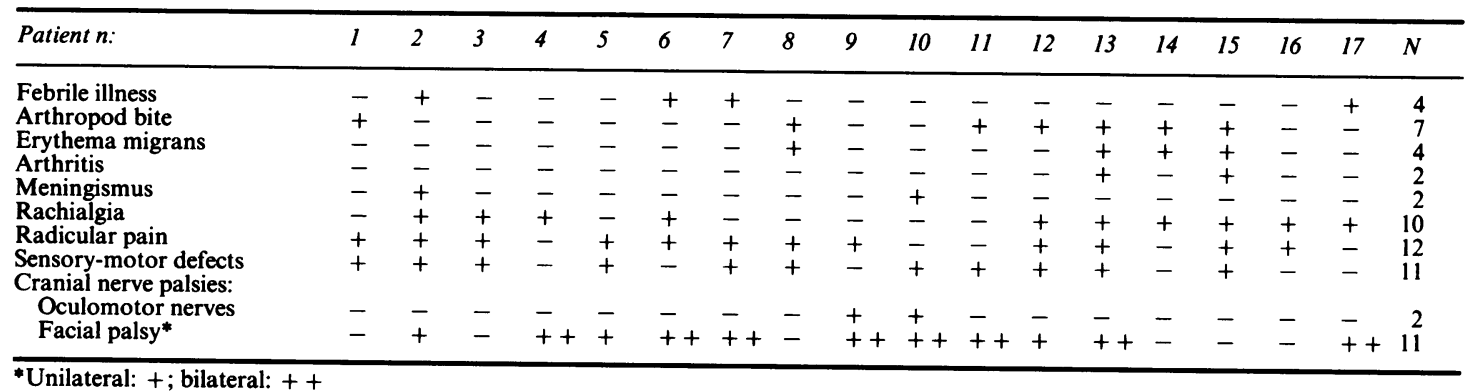

*Unilateral: + ; bilateral: + + 
September 1979. Six days later a right facial palsy appeared followed by a left one a few days later. The neurological examination was otherwise normal. No sensory-motor deficit was noted and muscle reflexes were all present. He did not recover from the right facial palsy.

Patient 5 A 66 year old woman was hospitalised in September $\mathbf{8 0}$ for a left brachial neuritis soon followed by a left facial palsy and a paresis of the right upper and lower limbs. The left arm was painful and paraesthesiae were noted in the region of $\mathrm{C} 8$ and $\mathrm{T} 1$ dermatomes. No tick bite was reported. Deep-tendon reflexes were absent in the upper limbs. Electromyography disclosed signs of denervation in all muscles of the upper limbs. Recovery was slow but complete without specific treatment. Six years later, the patient developed a senile dementia of the Alzheimer type.

Patient 6 A 29 year old man complained in April 81 from malaise, fever, rachialgia, hypoaesthesia in the upper thoracic region and ageusia. A bilateral facial palsy appeared on 14 April. Neurological examination was otherwise normal. Three months later, the facial palsy persisted without improvement.

Patient 7 At the end of June 81, a 36 year old man had fever with moderate asthenia. On 4 July, a right facial palsy appeared followed by a left one 2 days later. Neurological examination revealed a moderate quadriparesis, a distal hypoaesthesia and a complete areflexia. Spontaneous pain was noted in the region of the right T7 dermatome. Recovery was complete except for the facial palsies which were still present 1 year later.

Patient 8 A 72 year old man noted in September 1981 the appearance of erythema on the inner side of the left thigh. After a delay of several weeks, excruciating pain appeared in the region of the left L4 dermatome, accompanied by absence of the knee reflex and a weakness of the left quadriceps. The patient recovered completely with only a symptomatic treatment.

Patient 9 A 65 year old man complained of diplopia in August 1982 due to weakness of the left lateral rectus muscle. Ten days later, he developed a complete left facial palsy, followed 6 days later by a right one. Neurological examination revealed a facial diplegia, a complete left ophthalmoplegia but was otherwise normal. Corticosteroids were started, and the symptoms disappeared slowly. In March 1983 , the neurological examination was normal.

Patient 10 A 57 year old man suffered from left thoracic pain radiating towards both upper limbs in mid-August 1983. On 20 August, a left facial palsy appeared followed by a right one 5 days later. On 26 August, he complained of diplopia due to a right 6 th nerve palsy. In addition, neurological examination revealed a generalised areflexia and a slight proximal weakness of both lower limbs. The patient left hospital against medical advice and no follow-up was possible.

Patient 11 A 59 year old woman examined in August 1983 was suffering from a bilateral facial palsy accompanied by a left brachial neuritis and aching pain in the left arm. She remembered several "insect" bites 1 month before. Recovery was complete.

Patient 12 A 64 year old man was bitten by an "insect" in the left thigh at the end of May 1985 and developed a marked local oedema which disappeared spontaneously. A few days later he suffered from severe shooting pain in the right arm in the region of the C8-T1 dermatomes, followed by a weakness of the right hand and a left facial palsy on 25 June. In addition, neurological examination showed a hypoaesthesia on the midline of the abdomen and in the right and left C8-T1 dermatomes. Muscle stretch reflexes were present but weak; Babinski signs were noted bilaterally, as well as a transitory dysuria. Treatment with ampicillin was started and recovery was complete.

Patient 13 A 54 year old woman was bitten by an "insect" in the left groin region on 15 June 1985. An erythema appeared for 3 weeks, which migrated towards the thigh and the abdomen. In July the patient complained of rachialgia and polyarthritis. In August a bilateral facial palsy was observed. In addition, the left knee reflex was weak, and a slight hypoaesthesia was noted in the left thigh. She recovered quickly under penicillin treatment.

Patient 14 A 64 year old woman was bitten by an "insect" on the left thigh in July 85; local erythema appeared which persisted for 1 month. On 25 August, the patient complained of pain located between the shoulders with nocturnal paroxysms. On 17 September, the neurological examination was normal. Penicillin treatment was started and the pain disappeared slowly.

Patient 15 A 57 year old woman was bitten in her garden in Brussels by an insect at the end of June 1986 in the right axillary region. She developed thereafter an erythema migrans. In mid-July nuchal pain appeared and increased during the 2 following weeks causing severe insomnia. The patient also noticed radicular pain in the right C8-T1 area and a weakness of the triceps brachialis. Neurological examination revealed an absence of the right tricipital reflex and hypoaesthesia of the inner side of the right arm and hand. Pain disappeared quickly with penicillin treatment and neurological recovery was good. One month later, a short episode of arthritis at the level of the right wrist rapidly receded under anti-inflammatory treatment.

Patient 16 A 41 year old man complained of backache radiating to the anterior thoracic area in August 1986, during holidays in the South of France. No insect bite or erythema migrans were noted. As the pain worsened the patient returned to Belgium for hospitalisation. Neurological examination was normal. With penicillin treatment, the rachialgia diappeared quickly and the patient was discharged free of pain.

Patient 17 A 35 year old man presented with a febrile illness at the end of August 1986, followed by rachialgia. No insect bite or erythema migrans were noted. Fever disappeared within 1 week but a bilateral facial palsy occurred 10 days later. Neurological examination showed moreover a left biceps areflexia, but was otherwise normal. The facial diplegia recovered within 2 months after penicillin therapy.

\section{(b) A case characterised by encephalitis and myelitis}

Patient 18 A 35 year old man developed speech difficulties first during 1 hour in February 1981 and thereafter for 45 min in March 1981 with paraesthesiae in the right thumb and right face. Neurological examination showed a bilateral Babinski's sign and the first CSF examination revealed a high protein content, oligoclonal bands and increased titre of anti-herpes antibodies. A tentative diagnosis of benign herpetic encephalitis was made and the patient was dis- 
charged without complaint. In July 1981, the patient presented impotency, urinary urgency and partial fecal incontinence. Only bilateral extensor plantar responses were observed at neurological examination. In November 1981, ataxia and weakness of the legs, right more than left, appeared, followed 3 months later by diplopia, dysarthria, dysmetria and a right hemiparesis. In February 1982, one year after onset and for the first time, the serology for syphilis was positive in the CSF (VDRL and TPHA titres: $1 / 4$; IF titre: $1 / 40$ ) but not in the serum. A treatment with ampicillin was started. However, this positive serology was not supported by the $T$ pallidum immobilisation test (Nelson) which was negative. Antibiotics were stopped and the patient's condition recovered slightly. Two years later, neurological examination showed a slight paresis of the right leg, a bilateral Babinski's sign and a partial fecal incontinence; a stick was needed for walking. Cerebellar function and cranial nerves were normal.

\section{Serological data (table 2)}

High levels of total antibodies against $B$ burgdorferi were detected in the sera of all patients by our ELISA test. In contrast, serology for syphilis was negative. It should be noted that the highest titre were observed 2 to 3 months after clinical onset or arthropod bite and were still high 7 months later (Patient 9) and even 4.5 and 6 years later (Patients 18 and 5, respectively). IgM antibodies were less often detected being present in only 11 out of 17 patients tested. Even during the first month of the disease, the IgM test was sometimes negative (Patients 6, 10,11) but remained positive after 7 months in Patient 9.

\section{CSF data (table 3)}

CSF analysis revealed pleocytosis in all patients (range: 10 to $416 \mathrm{cells} / \mathrm{mm}^{3}$ mostly lymphocytes), a high total protein content in all but three patients (Patients 11, 14, 15), and oligoclonal bands in all but one patient (Patient 7). These oligoclonal bands disappeared in two cases during follow-up (Patients 5 and 9). In patient 18 with encephalomyelitis, oligoclonal bands although less numerous and more faint, were present 4.5 years after clinical onset and 3 years after treatment. The local humoral immune response was also assessed by the calculation of indices for IgG, IgA and IgM. The IgG index was high at least once during the follow-up in 14 cases out of 18 , the $\operatorname{IgA}$ index, in 13 cases out of 17 and the IgM index in all the 17 cases tested. In patients from whom serial samples were available these Ig indices returned to normal or near normal values with (Patients $12,16,18$ ) or without (Patient 9) antibiotic treatment. It should be noted that the ELISA test for the total Ig antibodies against $B$ burgdorferi was positive for the CSF of 12 patients out of 17 tested whereas the test was positive for the sera of all these patients. Negative CSF tests for $B$ burgdorferi antibodies were associated either with the absence of oligoclonal bands (patient 7) or with only a modest increase of the Ig indices (patients 1 , $6,14,15)$.

\section{Discussion}

Lymphocytic meningoradiculitis

The clinical features of our patients with lymphocytic meningoradiculitis due to $B$ burgdorferi are quite sim- ilar to those described for 100 European patients by Ackermann et al. ${ }^{25}$ An intense radicular pain and diffuse rachialgia are reported by most patients (70 and $59 \%$, respectively, in our series) but surprisingly meningeal signs are rarely observed $(12 \%)$. The peripheral nerve involvement was often asymmetrical and showed a great variety in localisation; it often started and was more severe in the region of initial pain. Facial palsy, unilateral in three and bilateral in eight patients, was very common $(65 \%)$ and was not associated with other sensory-motor defects in patients 4, 6 and 17. In fact, in patients 4 and 17, facial diplegia was the sole neurological sign; involvement of the oculomotor nerves was present in two cases (Patients 9 and 10). Minimal signs of spinal cord involvement, such as an extensor plantar response in Patient 12, have already been reported. ${ }^{25}$

The less frequent occurrence of arthritis in the European form of $B$ burgdorferi infections (two out of 17 in our series) is a distinct feature compared with Lyme disease. Only seven patients reported an

Table 2 Detection of antibodies against B burgdorferi in sera from patients with lymphocytic meningoradiculitis or encephalomyelitis by an ELISA test

\begin{tabular}{|c|c|c|c|}
\hline Patient No & $\begin{array}{l}\text { Interval between clinical } \\
\text { onset (or arthropod bite }{ }^{*} \text { ) } \\
\text { and sampling (days) }\end{array}$ & $\begin{array}{l}\text { ELISA } \\
\text { (total Ig) } \\
\text { OD } \\
\text { Cut off } 180\end{array}$ & $\begin{array}{l}\text { ELISA } \\
\text { (IgM) } \\
\text { OD } \\
\text { Cut off } 80\end{array}$ \\
\hline 1 & $46^{*}$ & 454 & 58 \\
\hline 2 & 58 & 1287 & 64 \\
\hline 3 & 63 & 1246 & 156 \\
\hline 4 & 18 & 1109 & 130 \\
\hline \multirow[t]{3}{*}{5} & ca 5 & 552 & 168 \\
\hline & 25 & 1032 & 284 \\
\hline & 6 years & 514 & 51 \\
\hline \multirow[t]{2}{*}{6} & ca $\begin{array}{l}15 \\
23\end{array}$ & $\begin{array}{l}406 \\
456\end{array}$ & $\begin{array}{l}58 \\
73\end{array}$ \\
\hline & 30 & 548 & 77 \\
\hline \multirow[t]{2}{*}{7} & 10 & 617 & 181 \\
\hline & 24 & 818 & 213 \\
\hline 8 & 58 & 1222 & 236 \\
\hline \multirow[t]{3}{*}{9} & 15 & 563 & 252 \\
\hline & 31 & 629 & 192 \\
\hline & 215 & 1518 & 111 \\
\hline 10 & ca 21 & 998 & 73 \\
\hline & 28 & 874 & 46 \\
\hline 11 & ca $30^{*}$ & 1035 & 35 \\
\hline \multirow[t]{3}{*}{12} & ca $30^{*}$ & 621 & 173 \\
\hline & $35^{*}$ & 595 & 150 \\
\hline & $47^{*}$ & 875 & 316 \\
\hline 13 & $103^{*}$ & 455 & 80 \\
\hline \multirow[t]{2}{*}{14} & $71^{*}$ & 909 & 236 \\
\hline & $120^{*}$ & 1372 & 255 \\
\hline \multirow[t]{2}{*}{15} & $52^{*}$ & 371 & 149 \\
\hline & $94^{*}$ & 214 & 133 \\
\hline \multirow[t]{2}{*}{16} & 27 & 809 & 100 \\
\hline & 33 & 693 & 167 \\
\hline \multirow[t]{4}{*}{17} & ca 25 & 711 & 164 \\
\hline & 31 & 684 & 262 \\
\hline & 40 & 673 & 317 \\
\hline & 72 & 1025 & 211 \\
\hline \multirow[t]{4}{*}{18} & ca 30 & $>2000$ & 58 \\
\hline & 60 & 1439 & 80 \\
\hline & 1 year & 870 & 35 \\
\hline & 4.5 years & 991 & 85 \\
\hline
\end{tabular}

.


Table 3 CSF findings in patients with lymphocytic meningoradiculitis and encephalomyelitis due to Borrelia burgdorferi

\begin{tabular}{|c|c|c|c|c|c|c|c|c|}
\hline \multirow[b]{2}{*}{ Patients No } & \multirow{2}{*}{$\begin{array}{l}\text { Interval between clinical onset } \\
\text { (or arthropod bite*) and } \\
\text { sampling (days) }\end{array}$} & \multirow[b]{2}{*}{$\begin{array}{l}\text { Protein content } \\
\text { (g/l) } N<0.55\end{array}$} & \multirow[b]{2}{*}{$\begin{array}{l}\text { Cells/mm } \mathrm{m}^{3} \\
\text { (\% lymphocytes) }\end{array}$} & \multirow[b]{2}{*}{$\begin{array}{l}\text { Oligoclonal } \\
\text { bands }\end{array}$} & \multicolumn{3}{|l|}{ Indices for } & \multirow{2}{*}{$\begin{array}{l}\text { ELISA for } \\
\text { Borrelia Antibodies } \\
\text { Cut off } 80\end{array}$} \\
\hline & & & & & $\stackrel{\operatorname{Ig} G}{N}<0.69$ & $\begin{array}{l}\operatorname{Ig} A \\
<0.45\end{array}$ & $\begin{array}{l}\text { IgM } \\
<0.079\end{array}$ & \\
\hline 1 & $46^{*}$ & 0.76 & $119(100)$ & + & 0.75 & ND & ND & 136 \\
\hline 2 & 58 & 0.65 & $43(75)$ & + & 0.60 & $1 \cdot 14$ & $2 \cdot 62$ & 278 \\
\hline 3 & 63 & $2 \cdot 24$ & $270(96)$ & + & $2 \cdot 22$ & 1.69 & 1.79 & 1247 \\
\hline 4 & 18 & 0.61 & $78(83)$ & + & $1 \cdot 46$ & 0.34 & 2.48 & 389 \\
\hline 5 & ca 5 & $1 \cdot 36$ & $101(93)$ & + & 0.98 & $1 \cdot 07$ & 1.67 & 571 \\
\hline & 25 & 1.46 & $82(93)$ & + & 0.89 & 1.45 & 1.56 & ND \\
\hline & 6 years & 0.50 & 2 & - & 0.60 & 0.50 & $0 \cdot 10$ & 46 \\
\hline \multirow[t]{3}{*}{6} & ca 15 & 0.53 & $106(99)$ & + & 0.78 & 0.45 & 0.16 & 48 \\
\hline & 23 & 0.46 & $57(84)$ & + & 0.71 & 0.44 & 0.17 & ND \\
\hline & 30 & 0.73 & $90(96)$ & + & 0.65 & 0.47 & 0.19 & ND \\
\hline \multirow[t]{2}{*}{7} & ca 10 & 0.93 & $42(93)$ & - & 0.72 & 0.55 & 0.46 & 64 \\
\hline & 24 & $1 \cdot 31$ & 14 & - & 0.73 & 0.52 & 0.30 & ND \\
\hline 8 & 58 & 0.96 & $103(90)$ & + & $1 \cdot 17$ & 0.41 & 0.89 & 598 \\
\hline \multirow[t]{4}{*}{9} & 15 & $1 \cdot 17$ & $187(86)$ & + & 0.58 & 0.38 & 0.47 & 215 \\
\hline & 31 & $1 \cdot 32$ & $408(54)$ & + & 0.85 & 0.65 & 1.43 & ND \\
\hline & 84 & 0.30 & $30(100)$ & - & 0.45 & 0.85 & 0.36 & 113 \\
\hline & 215 & 0.37 & 1 & - & 0.47 & 0.52 & $0 \cdot 11$ & 95 \\
\hline \multirow[t]{3}{*}{10} & 15 & 1.90 & $400(96)$ & + & ND & ND & ND & ND \\
\hline & 21 & 0.64 & $605(89)$ & + & 1.66 & 0.54 & $1 \cdot 28$ & ND \\
\hline & 28 & 0.45 & $68(88)$ & + & 1.75 & 0.57 & 1.62 & 550 \\
\hline 11 & ca $30^{*}$ & 0.36 & $136(100)$ & + & 0.95 & 0.32 & 0.45 & ND \\
\hline \multirow[t]{3}{*}{12} & ca $30^{*}$ & $3 \cdot 25$ & $416(90)$ & + & 0.65 & $3 \cdot 1$ & 0.40 & 1031 \\
\hline & $35^{*}$ & 1.70 & $182(94)$ & + & 0.62 & $10 \cdot 7$ & $31 \cdot 5$ & 1044 \\
\hline & $47^{*}$ & 1.00 & $138(100)$ & + & 0.49 & 0.68 & $6 \cdot 3$ & 325 \\
\hline \multirow[t]{2}{*}{13} & ca $60^{*}$ & $2 \cdot 20$ & $250(90)$ & + & 1.41 & 2.91 & $2 \cdot 02$ & 881 \\
\hline & $103^{*}$ & 0.47 & $24(98)$ & + & $2 \cdot 06$ & 3.89 & $1 \cdot 72$ & 60 \\
\hline \multirow[t]{2}{*}{14} & $71^{*}$ & 0.30 & $10(100)$ & + & 0.69 & 0.36 & $0 \cdot 10$ & 31 \\
\hline & $120^{*}$ & 0.24 & 1 & + & 0.43 & 0.50 & 0.06 & 71 \\
\hline \multirow{4}{*}{$\begin{array}{l}15 \\
16\end{array}$} & $52^{*}$ & 0.35 & $11(98)$ & + & 0.44 & 0.39 & $0 \cdot 28$ & 25 \\
\hline & 27 & $1 \cdot 50$ & 130 & + & 0.61 & 0.56 & 0.19 & 184 \\
\hline & 33 & $2 \cdot 10$ & 60 & + & 0.75 & 1.08 & 0.74 & \\
\hline & 68 & $2 \cdot 25$ & $19(100)$ & + & 0.51 & 0.73 & 0.36 & 46 \\
\hline \multirow[t]{3}{*}{17} & ca 25 & 1.08 & $340(88)$ & + & 1.02 & $2 \cdot 48$ & 3.95 & 1160 \\
\hline & 35 & 1.05 & $172(98)$ & + & 0.71 & 1.06 & 1.02 & 738 \\
\hline & 66 & 0.47 & $22(98)$ & + & 1.09 & $1 \cdot 26$ & $1 \cdot 81$ & 616 \\
\hline \multirow[t]{6}{*}{18} & ca 30 & $1 \cdot 26$ & $134(91)$ & + & ND & ND & ND & 1286 \\
\hline & 60 & 1.65 & $102(98)$ & + & ND & ND & ND & 1067 \\
\hline & 88 & $1 \cdot 74$ & $168(89)$ & + & ND & ND & ND & 1330 \\
\hline & 223 & $2 \cdot 37$ & $163(80)$ & + & ND & ND & ND & 1356 \\
\hline & 1.1 year & 2.55 & $122(80)$ & + & 1.84 & 0.87 & 0.57 & 1491 \\
\hline & 4.5 years & 0.38 & 1 & + & 0.67 & 0.46 & 0.038 & ND \\
\hline
\end{tabular}

"insect" bite ( $41 \%)$ and erythema chronicum migrans was present in four of these patients, not in the other patients. In the series of Ackermann et al, ${ }^{25} 37$ out of 100 patients reported such a tick or "insect" bite. The seasonal distribution of our cases as a function of onset of the disease is quite characteristic: one case each in April and May, three cases each in June and July, six cases in August and three cases in September.

The outcome was favourable in all patients either untreated $(\mathrm{N}=11)$ or treated $(\mathrm{N}=6)$. The latter recovered faster from pains and motor defects. It should be noted that one untreated patient (Patient 3) presented late exacerbation of his neurological signs 9 months after onset of the disease before complete spontaneous recovery and that facial palsies persisted in three other untreated patients (Patients 4, 6, 7).

\section{Encephalomyelitis}

Brain and spinal cord involvement may occur in infections due to $B$ burgdorferi which results in the development of a chronic severe disabling meningoencephalomyelitis of several years' duration, as illustrated by our patient 18. False positive tests for syphilis, as observed only in a late CSF from this patient have already been reported by Garin and Bujadoux. ${ }^{3}$ By chance, antibiotic treatment was started because of this false positive serology and the patient recovered partially. Such patients may be erroneously considered as having multiple sclerosis if serological tests for the detection of antibodies against $B$ burgdorferi are not performed. ${ }^{26}$

\section{Serological tests}

As $B$ burgdorferi infections may be responsible for a pleomorphic clinical picture including lymphocytic meningoradiculitis and chronic encephalitis, serological tests such as our ELISA system are of great value in order to establish the correct diagnosis. However, it is now well known that patients with syphilis have frequently false positive results against $B$ burg- 
dorferi antigens. ${ }^{27}$ For this reason, all samples which are positive for $\boldsymbol{B}$ burgdorferi should also be tested for a syphilitic serology. The latter was negative in all our patients, except for the false positive response observed in one CSF sample from patient 18.

The specific IgM response which is sometimes not detectable during the first weeks of infection (Patients $6,10,11)$, usually peaks during the fourth through the sixth week and may persist for months (Patient 9). ${ }^{112728}$ Specific IgG titres increase more slowly, are highest months after onset and may remain elevated for years after clinical remission (Patients 5 and 18)..$^{112728}$

\section{CSF data}

All patients had CSF abnormalities, especially pleocytosis, high protein content, oligoclonal bands and high Ig indices. A local IgM production as assessed by the IgM index was always observed. This feature is shared with active neurosyphilis and was already reported by Felgenhauer. ${ }^{29}$ Even in untreated patients, this local immune response may cease spontaneously and oligoclonal bands may disappear (Patients 5 and 9). In patient 18 with encephalomyelitis, oligoclonal bands although less numerous and more faint were always present 4.5 years after clinical onset but the Ig indices returned to normal values. Although pleocytosis was observed in all cases and oligoclonal bands, in all but one, our ELISA test was positive in only 12 out of 17 patients tested. In contrast, serum samples were positive at least once in all patients. Our results are different from those observed by Swedish authors ${ }^{30}$ who reported that $25 \%$ of their 45 patients with chronic meningitis had significantly elevated titres of antibody to $B$ burgdorferi in CSF but not in serum. This could be due to the heterogeneity of $B$ burgdorferi strains which could result in infections more or less systemic or restricted to the central nervous system.

In conclusion, neurological disorders due to $B$ burgdorferi infections are not rare in Belgium, even in Brussels and its periphery. The clinical picture may be very pleomorphic and severe chronic encephalomyelitis may occur. Serological tests are now available for routine use and are invaluable for establishing the correct diagnosis. A specific treatment (penicillin G, 20,000,000 units per day during 10 days) ${ }^{3132}$ should be systematically given in order to relieve quickly pain and more importantly, to avoid possible late complications such as brain and spinal cord involvement.

We thank Mrs MP Van Antwerpen for skilful technical assistance and $\mathrm{Dr} T$ Wilkins for reviewing the manuscript. This work was supported by grant No 3.4529.79 from the Fonds de la Recherche Scientifique Médicale.

\section{References}

1 Hinthorn DR, Baker LH, Romig DA, Liu C. Recurrent conjugal neuralgia caused by herpes virus hominis type 2. JAMA 1976;236:587-8.

2 Gardner-Thorpe C, Foster JB, Barwick DD. Unusual manifestations of herpes zoster. A clinical and electrophysiological study. J Neurol Sci 1976;28:427-47.

3 Garin C, Bujadoux C. Paralysie par les Tiques. J Med Lyon 1922;71:765-7.

4 Bannwarth A, Chronische lymphocytäre Meningitis, entzündliche Polyneuritis und "Rheumatismus". Ein Betrag zum Problem "Allergie und Nervensystem". Arch Psychiat Nervenkr 1941;115:284-376.

5 Reik L, Steere AC, Bartenhagen NH. Shope RE, Malawista SE. Neurologic abnormalities of Lyme disease. Medicine 1979;58:281-94.

6 Steere AC, Malawista SE, Snydman DR, et al. Lyme arthritis. An epidemic of oligoarticular arthritis in children and adults in three Connecticut communities. Arthritis Rheum 1977;20:7-17.

7 Steere AC, Malawista SE, Hardin JA, Ruddy S, Askenase PW, Andiman WA. Erythema chronicum migrans and Lyme arthritis. The enlarging clinical spectrum. Ann Int Med 1977;86:685-98.

8 Steere AC, Broderich TF, Malawista SE. Erythema chronicum migrans and Lyme arthritis: Epidemiologic evidence for a tick vector. Am J Epidemiol 1978;108:312-21.

9 Burgdorfer W, Barbour AG, Hayes SF, Benach JL, Grunwaldt E, Davis JP. Lyme disease- a tick-borne spirochetosis? Science 1982;216:1317-9.

10 Benach JL, Bosler EM, Hanrahan JP, et al. Spirochetes isolated from the blood of two patients with Lyme disease. $N$ Engl $J$ Med 1983;308:740-2.

11 Steere AC, Grodzicki RL, Kornblatt AN, et al. The spirochetal etiology of Lyme disease. $N$ Engl J Med 1983;308:733-40.

12 Ryberg B, Nilsson B, Burgdorfer W, Barbour AG. Antibodies to Lyme-disease spirochaete in European lymphocytic meningoradiculitis (Bannwarth's syndrome)? Lancet 1983;ii:519.

13 Pfister HW, Einhaupl K, Preac-Mursic V, Wilske B, Schierz G. The spirochetal etiology of lymphocytic meningoradiculitis of Bannwarth (Bannwarth's syndrome). J Neurol 1984;231:141-4.

14 Johnson RC, Schmid GP, Hyde FW, Steigerwalt AG, Brenner DJ. Borrelia burgdorferi sp nov etiologic agent of Lyme disease. Int J Syst Bacteriol 1984;34:496-7.

15 Wilske B, Preac-Mursic V, Schierz G. Antigenic heterogeneity of European Borrelia burgdorferi strains isolated from patients and ticks. Lancet 1985;i:1099.

16 Vandvik B, Sköldenberg B, Stiernstedt G. Tick-borne spirochaetal meningitis, meningoradiculitis and meningoencephalitis. A report of 15 cases identified by demonstration of intrathecal spirochaete-specific IgG antibody responses. Acta Neurol Scand 1984;70:379-80.

17 Ackermann R, Gollmer E, Rehse-Küpper B. Progressive Borrelien-Enzephalomyelitis, Chronische Manifestation der Erythema chronicum migrans Krankheit am Nerven system. Disch Med Wschr 1985;110:1039-42.

18 Reik L, Smith L, Khan A, Nelson W. Demyelinating encephalopathy in Lyme disease. Neurology 1985;35:267-9.

19 Kohler J, Kasper J, Kern U, Thoden U, Rehse-Küpper B. Borrelia encephalomyelitis. Lancet 1986;ii:35.

20 Rousseau JJ, Lust C, Zangerle PF, Bigaignon G. Acute transverse myelitis as presenting neurological feature of Lyme disease. Lancet 1986;ii:1222-3.

21 Masson PL, Cambiaso CL, Collet-Cassart D, Magnusson CGM, Richards CB, Sindic CJM, Particle Counting Immunoassay (PACIA). Meth Enzymol 1981;74:106-39.

22 Sindic CJM. Cerebrospinal fluid proteins in diseases of the nervous system. Thesis. Leuven: Nauwelaerts Printing, 1985.

23 Laterre EC. Les protéines du liquide céphalo-rachidien à l'état normal et pathologique. Thèse, Paris: Arscia Maloine, 1965.

24 Barbour AG. Isolation and cultivation of Lyme disease spi- 
rochetes. Yale J Biol Med 1984;57:521- -5.

25 Ackermann R, Hörstrup P, Schmidt R. Tick-borne meningopolyneuritis (Garin-Bujadoux, Bannwarth). Yale J Biol Med 1984;57:485-90.

26 Gay D, Dick G. Spirochaetes, Lyme disease, and multiple sclerosis. Lancet 1986;ii:685.

27 Craft JE, Grodzicki RL, Steere AC. Antibody response in Lyme disease: evaluation of diagnostic tests. ..J. Infect Dis 1984;149:789-95.

28 Craft JE, Grodzicki RL, Shrestha M, Fischer DK, Garcia-Blanco M, Steere AC. The antibody response in Lyme disease. Yale J Biol Med 1984;57:561-5.

29 Felgenhauer K. Differentiation of the humoral immune response in inflammatory diseases of the central nervous system. $J$ Neurol 1982;228:223-37.

30 Stiernstedt GT, Granström M, Hederstedt B, Sköldenberg B. Diagnosis of spirochetal meningitis by Enzyme-Linked Immunosorbent Assay and Indirect Immunofluorescence Assay in Serum and Cerebrospinal Fluid. $J$ Clin Microbiol 1985:21:819-25.

31 Steere AC, Pachner AR, Malawista SE. Neurologic abnormalities of Lyme disease: successful treatment with high does intravenous penicillin. Ann Int Med 1983;99:767-72.

32 Sköldenberg B, Garde A, Carlström A, Stiernstedt G, Kolmodin G, Nord CE. Chronic meningitis caused by a penicillinsensitive microorganism? Lancet 1983;i:75-8. 